\title{
PATHOGENIC AND \\ NON-PATHOGENIC AMOEBAE
}




\title{
PATHOGENIC AND NON-PATHOGENIC AMOEBAE
}

\author{
by \\ B. N. SINGH \\ PhD (Dublin), PhD, DSc (London), FNA (Emeritus Scientist, CSIR, Central Drug \\ Research Institute, Lucknow, India; formerly Deputy Director and Head of the Division \\ of Microbiology)
}

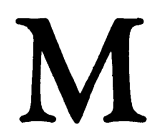




\author{
(C) B. N. Singh 1975
}

Softcover reprint of the hardcover 1st edition 1975

All rights reserved. No part of this book may be reproduced or transmitted in any form or by any means, without permission This book is sold subject to the standard conditions of the Net Book Agreement

\author{
First published 1975 by \\ THE MACMILLAN PRESS LTD \\ London and Basingstoke \\ Associated companies in New York \\ Dublin Melbourne fohannesburg and Madras \\ SBN 333183886
}

ISBN 978-1-349-02622-7 ISBN 978-1-349-02620-3 (eBook)

DOI 10.1007/978-1-349-02620-3 


\title{
Foreword
}

\author{
by \\ Cecil A. Hoare, DSc, FIBiol, FRS \\ Wellcome Museum of Medical Science, London
}

After the discovery of Entamoeba histolytica a century ago, it has been generally assumed that this was the only amoeba to be reckoned with as a human pathogen, causing amoebic dysentery and other forms of amoebiasis, while some species of this genus proved to be responsible for disease in lower vertebrates. It was also taken for granted that only parasites need be considered as possible pathogens. On the other hand, interest in the numerous free-living amoebae inhabiting fresh and foul waters as well as the soil, was largely academic, though it was known that some species play an important role in soil microbiology.

This preconceived notion has become untenable since the discovery, made within the last two decades, that free-living or limax-amoebae were infective to man and lower mammals, causing fatal disease affecting the central nervous system. This discovery not only revolutionised the very concept of parasitism, by breaking down the barrier separating free-living organisms from parasites, but presented medical science with an entirely new disease, the aetiology and epidemiology, as well as the control, of which are serious problems urgently in need of investigation. Though so far only two genera (Naegleria and Hartmannella) have been incriminated in the aetiology of exogenous amoebiasis, the potential pathogenicity of other free-living amoebae cannot be excluded without further studies.

Until now, information on limax-amoebae, scattered in the protozoological literature, has not been readily available. In this book, for the first time, the existing knowledge on these organisms has been brought together, thereby providing an exhaustive illustrated account dealing with their classification, morphology and bionomics, which should enable workers in this field to identify known and suspected pathogens, and to differentiate them from other species of amoebae. For comparison with endogenous amoebiasis, the relevant data concerning Entamoeba histolytica are also considered in some detail.

This comprehensive work could be accomplished only by such a recognised authority on the subject as Dr B. N. Singh, whose researches on free-living amoebae started in England over thirty-five years ago at the Rothamsted Experimental Station in Harpenden and continued fourteen 


\section{Foreword}

years later and up to date in India at the Central Drug Research Institute in Lucknow, where the scope of his investigations was widened by inclusion of E. histolytica.

Dr Singh has drawn upon his wide experience, derived from original observations on amoebae, to produce a monograph which provides protozoologists with a comprehensive account of the order Amoebida. Moreover, medical workers and parasitologists will find in it all the essential information required for their investigations on exogenous amoebiasis. 


\section{Preface}

The amoebae belonging to the order Amoebida have been grouped into parasitic and free-living. Before the work of F. Lösch in 1875 amoebae attracted little attention as disease-producing organisms in man. Lösch found amoebae in stools of patients and in ulcers of the colon. This anaerobic amoeba was later named Entamoeba histolytica Schaudinn, 1903. It has its primary site of infection in the intestinal tract, as a result of ingestion of cysts. In addition to this species, human beings may be infected with a number of non-pathogenic amoebae (Entamoeba coli, E. gingivalis, Endolimax nana and Iodamoeba buetschlii). It was inconceivable even to imagine that free-living amoeba may cause disease in man, for even the histolytica-like Entamoeba moshkovskii is not infective to any animals. The discovery from 1958 onwards that certain species of aerobic small free-living amoebae, belonging to the genera Hartmannella and Naegleria, cause fatal meningo-encephalitis in animals and man, by the entry of trophozoites through the nose during swimming or bathing in fresh water, has abolished the artificial barrier existing between parasitic and free-living amoebae, and has provided another mechanism of infection. C. A. Hoare in 1972 has suggested the term exogenous amoebiasis for the disease caused by aerobic free-living amoebae, to distinguish it from endogenous amoebiasis caused by anaerobic E. histolytica.

The book deals with soil as a suitable habitat for free-living amoebae, historical development of soil protozoology, methods of cultivating soil amoebae and enumerating their numbers in soil, and possible phylogenetic classification of amoebae. These studies have led to the isolation and culture of pathogenic free-living forms from soil, sewage sludge, fresh water, animal and human tissues, and for their correct identification. Amoebiasis caused by E. histolytica is one of the most serious diseases in tropical and semi-tropical regions of the world. The known antiamoebic drugs seem to have little or no effect on the cystic stage of E. histolytica resulting in the relapse of the disease after the cessation of therapy. The hope of achieving a complete cure in chronic amoebiasis lies in the discovery of chemotherapeutic agents that, in addition to having antiamoebic property, should be cysticidal, or prevent amoebae from forming cysts, or cause excystment of cysts. Moreover, the nature of changes which occur when E. histolytica ceases to be a harmless lumen dweller and invades the 


\section{Preface}

mucosa is unknown. Therefore, the methods used in the culture of anaerobic amoebae, factors responsible for encystation and excystation in protozoa, the chemical composition and permeability of cyst-wall and the pathogenicity of E. histolytica are presented, with a view to the rational design and synthesis of chemotherapeutic agents. The information contained in this book, at present available mostly in papers published in numerous journals, is not accessible to students. It should stimulate teaching and research in soil, medical and veterinary protozoology.

I wish to convey my sincere thanks to C. A. Hoare, FRS and R. A. Neal for going through the manuscript and for making valuable suggestions. I am grateful to my colleagues C. R. Krishna Murti for the help in writing the section on encystation in protozoa, and G. P. Dutta and B. N. K. Prasad in the preparation of the references. In particular I wish to thank M. L. Dhar, the Director, for encouraging basic research on amoebae and for providing the necessary facilities. My thanks are also due to $S$. Banerii, of the photographic and drawing section, for drawing a number of the illustrations and to R. P. Nigam for typing the manuscript.

I also wish to express my grateful thanks to the publishers, editors and scientific organisations of Annals of Applied Biology, Advances in Parasitology, Archiv für Protistenkunde, The Royal Society (London), Indian National Science Academy, Council of Scientific and Industrial Research (New Delhi), Journal of Cell Biology, Bhabha Atomic Research Centre (Bombay), Journal of General Microbiology, British Journal of Experimental Pathology and Current Science and Journal of Protozoology, for their kind permission to reproduce figures and tables in this book. Thanks are also due to R. A. Neal, C. R. Krishna Murti, S. C. Agarwala and G. P. Dutta for permission to reproduce some of the figures and tables.

Central Drug Research Institute,

Lucknow, India, 1975

B. N. Singh 


\section{Contents}

Foreword

Preface

1 AEROBIC SMALL FREE-LIVING AMOEBAE 1

Soil as a suitable habitat 1

Historical development of soil protozoology 2

Selectivity in bacterial food in culture and in soil 4

Methods of cultivation and enumeration in soil 18

2 POSSIBLE PHYLOGENETIC CLASSIFICATION OF THE ORDER AMOEBIDA 33

3 DESCRIPTION OF SOME IDENTIFIED AEROBIC FREE-LIVING AMOEBAE 65

4 AEROBIC FREE-LIVING AMOEBAE AS ANIMAL AND HUMAN PATHOGENS 101

5 ANAEROBIC AMOEBAE 116

Methods of cultivation $\quad 116$

Evaluation of antiamoebic agents against Entamoeba histolytica in vitro 133

Laboratory animals in chemotherapeutic studies 137

Pathogenicity of Entamoeba histolytica 142

Unsolved problems in chemotherapy of amoebiasis caused by $\begin{array}{ll}\text { Entamoeba histolytica } & 160\end{array}$

Conclusion 199

References $\quad 203$

Index 232 